\title{
Emodin reverses gemcitabine resistance in pancreatic cancer cells via the mitochondrial apoptosis pathway in vitro
}

\author{
DIAN-LEI LIU ${ }^{1 *}$, HEQI BU ${ }^{1 *}$, HONG LI ${ }^{2 *}$, HUI CHEN ${ }^{1}$, HONG-CHUN GUO ${ }^{1}$, ZHAO-HONG WANG ${ }^{1}$, \\ HONG-FEI TONG ${ }^{1}$, ZHONG-LIN NI ${ }^{1}$, HAI-BIN LIU ${ }^{1}$ and SHENG-ZHANG LIN ${ }^{1}$ \\ ${ }^{1}$ Department of Surgery, The Second Affiliated Hospital of Wenzhou Medical College, No. 109, \\ West Xue-yuan Road, Wenzhou 325027; ${ }^{2}$ Wenzhou Vocational College of Science \\ and Technology, Wenzhou Liuhong Road No. 1000, Wenzhou 325000, P.R. China
}

Received September 20, 2011; Accepted November 10, 2011

DOI: 10.3892/ijo.2011.1285

\begin{abstract}
Gemcitabine resistance is a common problem of pancreatic cancer chemotherapy, and how to reverse it plays an important role in the treatment of pancreatic cancer. This study investigated the effect of emodin on the gemcitabine-resistant pancreatic cancer cell line SW1990/Gem, and explored the potential mechanism of its action. SW1990/Gem was obtained by culture of the pancreatic cancer cell line SW1990 in vitro by intermittently increasing the concentration of gemcitabine in the culture medium for 10 months, observing the morphology using inverted microscopy. SW1990/Gem cells were pretreated with emodin $(10 \mu \mathrm{M})$ for different periods followed by treatment with gemcitabine $(20 \mu \mathrm{M})$ for $48 \mathrm{~h}$; cell proliferation was tested by MTT assay. SW1990/Gem cells were treated by emodin with different concentrations for $48 \mathrm{~h}$, cell apoptosis was detected by flow cytometry (FCM). The expression of gene and protein, such as MDR-1 (P-gp), NF-кB, Bcl-2, Bax, cytochrome-C (cytosol), caspase- 9 and -3 were measured by RT-PCR and Western blotting. The function of P-gp in SW1990/Gem cells was checked by FCM. The results showed that the SW1990/Gem cells changed greatly in morphology and the resistance index was 48.63. Emodin promoted cell apoptosis of the gemcitabine-resistant cell line SW1990/Gem in a dose-dependent manner. Emodin enhanced the SW1990/Gem cell sensitivity to gemcitabine in a time-dependent manner. Emodin monotherapy or combination with gemcitabine both decreased the gene and protein expression levels of MDR-1 (P-gp), NF- $\mathrm{BB}$ and Bcl-2 and inhibited the function of P-gp, but increased the expression levels of Bax, cytochrome-C (cytosol), caspase- 9 and -3 , and promoted cell apoptosis. This demonstrated that emodin had a reversing effect on the gemcitabine-resistant cell line SW1990/Gem, possibly via
\end{abstract}

Correspondence to: Dr Sheng-Zhang Lin, The Second Affiliated Hospital of Wenzhou Medical College, No. 109, West Xue-yuan Road, Wenzhou 325027, P.R. China

E-mail:wzf21sz@163.com

${ }^{*}$ Contributed equally

Key words: emodin, reverse, pancreatic cancer, gemcitabine-resistance decreasing the function of P-gp and activating the mitochondrial apoptosis pathway in vitro.

\section{Introduction}

Pancreatic cancer is a common and highly malignant tumor of the digestive system. In recent years, the global morbidity and mortality of pancreatic cancer is increasing. In Europe, new cases of pancreatic cancer in 2006 were 60,000, and 59,000 cases of death, ranking fifth in cancer mortality in Europe (1). In the United States, new cases were 37,170 in 2006, and 33,370 cases of death; in 2010, new cases were 43140, ranking fourth in cancer mortality in the United States $(2,3)$. Surgical resection is the only hope to improve survival rate, but the vast majority of pancreatic cancer patients are diagnosed at advanced stage, and prognosis is poor, the average 5-year survival rate is less than 5\% (3). In addition to surgery, chemotherapy is still an important means to treat advanced pancreatic cancer, prevent post-surgical recurrence, prolong survival time and improve life quality. Gemcitabine is currently the best first-line chemotherapy to treat advanced pancreatic cancer (4), but due to acquired or intrinsic drug resistance of pancreatic cancer cells $(5,6)$, effect of using gemcitabine to treat pancreatic cancer is still not ideal (7), which causes patients treated with gemcitabine to suffer from side effects of chemotherapy without good treatment. Thus, it is particularly important to find a drug that can reverse the drug-resistance and enhance the treatment of gemcitabine. Emodin (6-methyl-1,3,8-tanthragallol), which is the main active monomer separated from Rheum, Polygonum, buckthorn and senna, is a tyrosine kinase II inhibitor, it has effects of anti-microbial activity (8-11), anti-inflammatory $(12,13)$, immunosuppression (14), anti-tumor $(15,16)$, and activity in protection of liver cells (17). Our team previously found emodin could promote apoptosis (16), and established the gemcitabine-resistance cell line SW1990/Gem, we confirmed that emodin could increase the sensibility of resistance cell line to gemcitabine through inhibiting the expression of $\mathrm{NF}-\kappa \mathrm{B}$ (18). However, it is still unclear whether emodin can reverse the gemcitabine-resistant human pancreatic cancer cells, thus this study mainly investigates the effect of emodin reversing the gemcitabine-resistance on SW1990/Gem cell line, and its possible mechanisms. 


\section{Materials and methods}

Chemicals and cell lines. The followings were purchased: Emodin (purity >98\%), MTT, DMSO (Sigma), gemcitabine (Eli Lilly and Co.), FBS, trypsin containing EDTA, Roswell Park Memorial Institute-1640 (RPMI-1640) (Gibco), BCA protein assay kit (Pik-day Institute of Biotechnology), Rhodamine123 (Rh123), Annexin V-FITC/PI apoptosis detection kit (Biological Development Co., Ltd. Nanjing KGI), RNA extraction kit (Life Technologies Co.); cDNAfirst strand synthesis kit (Fermentas), 2X Taq PCR MasterMix (Tiangen), P-gp, NF-кB, Bcl-2, Bax, cytochrome-C antibodies (Santa Cruz). Drug preparation: Emodin was dissolved in DMSO as a $0.2 \mathrm{mM}$ stock solution and stored at $-20^{\circ} \mathrm{C}$. DMSO concentration $<0.1 \%$ (it has no effect on cell proliferation when concentration was $<0.1 \%)$. Gemcitabine is reconstituted as a $0.02 \mathrm{mM}$ stock solution in sterile saline. Cell culture: The human pancreatic cancer cell line SW1990 was purchased from the American Type Culture Collection. Cells were cultured in RPMI-1640 medium, supplemented with $10 \%$ fetal calf serum (FCS), in a humidified atmosphere of $5 \% \mathrm{CO}_{2}$ and $95 \%$ air at $37^{\circ} \mathrm{C}$.

Establishment of gemcitabine-resistant human pancreatic cancer cell line SW1990/Gem. Gemcitabine-resistant pancreatic cancer cell line SW1990/Gem was obtained by culture of pancreatic cancer cell line SW1990 in vitro with intermittently increasing the concentration of gencitabine in the culture medium for 10 months. After cultivating SW1990 cells with different concentrations of gemcitabine for 1 week, we checked the cell death conditions and chose the concentration of median lethal dose $\left(\mathrm{LD}_{80}\right)$ (which could kill $80 \%$ cells) as the initial concentration to cultivate the resistant cell line. Cells were cultivated in this medium for $48 \mathrm{~h}$, and then incubated in RPMI-1640 medium without drugs. When cells grew stably and entered the logarithmic growth phase, they were passaged twice, and exposed to gemcitabine in double $\mathrm{LD}_{80}$ concentration, after nine concentration gradients and $\sim 10$ months of cultivation, they were finally incubated in RPMI-1640 medium without drugs for 2 months.

Morphological assay of gemcitabine-resistant cell line SW1990/ Gem. Two lines of logarithmic phase SW1990/Gem and SW1990 cells were incubated in a 6-well plate at a density of 100,000 cells per well for 2 days, and were observed by optical microscope (Nikon, TS100), and then were collected separately and fixed for electron microscopic observation of cell ultra-structures.

Sensitivity analysis of SW1990/Gem to gemcitabine. The logarithmic phase SW1990/Gem and SW1990 cells were incubated in a 96-well plate at a density of 4,000 cells per well. Cells were cultured in different concentrations $(20,40,80$ and $160 \mu \mathrm{M})$ of gemcitabine for $48 \mathrm{~h}$ after they adhered. Each group had 6-wells. The supernatant was discarded and $20 \mu \mathrm{l}$ MTT $(5 \mathrm{mg} / \mathrm{ml})$ was added with $180 \mu \mathrm{l}$ medium to each well, $4 \mathrm{~h}$ later the culture medium was removed and $150 \mu 1 \mathrm{DMSO}$ was added to each well. The plate was shaken by microplate shaker for $10 \mathrm{~min}$ and the absorbance (A) of samples was measured at $490 \mathrm{~nm}$ by automatic enzyme-linked immunosorbent assay. The experiment was repeated three times. The drug inhibition of cells was calculated by the following formula: Inhibition = 1-dosing group A/control group A x 100\%. Data was graphed on a semi-logarithmic curve with drug concentrations plotted on the $\mathrm{x}$-axis and cell inhibitions on the y-axis. SPSS software was used to calculate the 50\% inhibitory inhibition $\left(\mathrm{IC}_{50}\right)(19)$ and the resistance index $(\mathrm{RI})$. $\mathrm{RI}=\mathrm{IC}_{50}$ of resistance cell line $/ \mathrm{IC}_{50}$ of the sensitive cell line.

Effect of gemcitabine on SW1990/Gem proliferation after pretreatment with emodin. SW1990/Gem cells were incubated in a 96-well plate at a density of 4,000 cells per well overnight. Cells were pretreated with low emodin $(10 \mu \mathrm{M})$ for different periods $(12,24,36,48$ and $60 \mathrm{~h})$ and then incubated with gemcitabine for $48 \mathrm{~h}$. Emodin was not added to the control group, and it was directly incubated in gemcitabine for 48 h. The supernatant was discarded and MTT $(5 \mathrm{mg} / \mathrm{ml})$ was added, $4 \mathrm{~h}$ later the culture medium was removed and $150 \mu \mathrm{l}$ DMSO was added to each well. The plate was shaken by a microplate shaker for $10 \mathrm{~min}$ and absorbance (A) of samples were measured. Each group had 6-wells. The experiment was repeated three times, and the cell viability was calculated.

Effect of emodin on SW1990/Gem cell apoptosis. The logarithmic phase SW1990/Gem cells were incubated in a 6-well plate ( $4 \times 10^{5} /$ well), treated with different concentrations of emodin (10, $20,40,80$ and $160 \mu \mathrm{M})$ and the control group when cells were $80 \%$ confluent. Forty-eight hours later, cells were collected and centrifuged at $1000 \mathrm{rpm} / \mathrm{min}$ for $5 \mathrm{~min}$. Cells were washed with cold PBS 3 times and resuspended with $500 \mu \mathrm{l}$ binding buffer, then $5 \mu \mathrm{l}$ Annexin V-FITC was added, mixed, and cultured in the dark for $5 \mathrm{~min}$, adding $10 \mu \mathrm{l}$ PI for $5 \mathrm{~min}$. The fluorescence of cells was measured by flow a cytometer at $488 / 530 \mathrm{~nm}$. The experiment was repeated three times, and cells were analyzed with Cell Quest software.

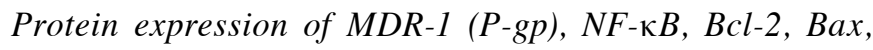
cytochrome-C (cytosol), caspase-9 and -3 were detected in SW1990/Gem and SW1990 by Western blotting. SW1990/Gem and SW1990 cells were collected, the cytoplasmic protein was evaluated with the mitochondrial/cytoplasmic protein isolation kit to detect cytochrome-C levels according to the instructions. Cells were lysed with RIPA, centrifuged at $12000 \mathrm{rpm} / \mathrm{min}$, collecting the supernatant. Protein concentrations were measured with BCA kit, then the amount of protein was equaled, in 10\% SDS-PAGE electrophoresis, PVDF membrane was transferred, then blocked with $5 \%$ skimmed milk powder, incubated with antibodies at $4{ }^{\circ} \mathrm{C}$ overnight, then washed with TBST and incubated with secondary antibodies for $2 \mathrm{~h}$, after washing with TBST and coloring with ECL, the membranes were exposed to X-rays. The experiment was repeated three times.

Protein expression of $P-g p, N F-\kappa B, B c l-2$, Bax, cytochrome-C, caspase-9 and -3 in SW1990/Gem after treatment with emodin and/or gemcitabine by Western blotting. SW1990/Gem was treated with emodin $(10 \mu \mathrm{M})$ and gemcitabine $(20 \mu \mathrm{M})$ alone or together for $48 \mathrm{~h}$, cytoplasmic protein was gathered with the mitochondrial/cytoplasmic protein isolation kit to detect cytochrome-C levels according to the instructions. The other steps were as above.

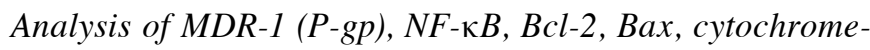
$C$, caspase-9 and -3 in SW1990/Gem after treatment with 
Table I. RT-PCR sequences of primers and the size of the sequences.

\begin{tabular}{llll}
\hline Gene & \multicolumn{1}{c}{ Sense primer } & \multicolumn{1}{c}{ Antisense primer } & PCR product (bp) \\
\hline MDR-1 & GAATCTGGAGGAAGACATGACC & TCCAATTTTGTCACCAATTCC & 259 \\
NF- $\mathrm{B}$ & AGCACAGATACCACCAAGACCC & CCCACGCTGCTCTTCTATAGCAAC & 300 \\
Bcl-2 & AGCCGGGAGAACAGGGTATG & ATCCAGGTGTGCATGCCG & 549 \\
Bax & ATGGCTGGGGAGACACCTGA & TGGGCGTCCCGAAGTAGGAA & 394 \\
Cyt-c & GCGTGTCCTTGGACTTAGAG & GGCGGCTGTGTAAGAGTATC & 241 \\
Caspase-9 & GGTTCTGGAGGATTTGGTGA & GACAGCCGTGAGAGAGAATGA & 325 \\
Caspase-3 & AGCAAACCTCAGGGAAACATT & GTCTCAATGCCACAGTCCAGT & 309 \\
GAPDH & AACGGATTTGGTCGTATTGGG & TCGCTCCTGGAAGATGGTGAT & 216 \\
\hline
\end{tabular}

emodin and/or gemcitabine by reverse transcription-PCR. After cultivating SW1990/Gem cells treated with emodin $(10 \mu \mathrm{M})$ and gemcitabine $(20 \mu \mathrm{M})$ alone or combined for 48 $\mathrm{h}$, cells were lysed by TRIzol and RNA was extracted, then the content of RNA was measured by UV spectrophotometer at $260 \mathrm{~nm}$. cDNA under the instruction of the first Fermentas cDNA strand synthesis kit was synthesized (Tiangen 2X Taq PCR MasterMix instruction) the PCR amplification conditions were: MDR-1, $94^{\circ} \mathrm{C} 30 \mathrm{sec}, 57^{\circ} \mathrm{C} 30 \mathrm{sec}, 72^{\circ} \mathrm{C} 30 \mathrm{sec}, 30$ cycles; $\mathrm{NF}-\kappa \mathrm{B}, 94^{\circ} \mathrm{C} 30 \mathrm{sec}, 54^{\circ} \mathrm{C} 30 \mathrm{sec}, 72^{\circ} \mathrm{C} 20 \mathrm{sec}, 30$ cycles; Bcl-2, $94^{\circ} \mathrm{C} 20 \mathrm{sec}, 58^{\circ} \mathrm{C} 20 \mathrm{sec}, 72^{\circ} \mathrm{C} 20 \mathrm{sec}, 35$ cycles; Bax, $94^{\circ} \mathrm{C}$ $30 \mathrm{sec}, 57^{\circ} \mathrm{C} 30 \mathrm{sec}, 72^{\circ} \mathrm{C} 20 \mathrm{sec}, 30$ cycles; cytochrome-C, $94^{\circ} \mathrm{C} 30 \mathrm{sec}, 60^{\circ} \mathrm{C} 30 \mathrm{sec}, 72^{\circ} \mathrm{C} 30 \mathrm{sec}, 35$ cycles; caspase- 9 , $94^{\circ} \mathrm{C} 30 \mathrm{sec}, 56^{\circ} \mathrm{C} 30 \mathrm{sec}, 72^{\circ} \mathrm{C} 30 \mathrm{sec}, 35$ cycles; caspase-3, $94^{\circ} \mathrm{C} 30 \mathrm{sec}, 57^{\circ} \mathrm{C} 30 \mathrm{sec}, 72^{\circ} \mathrm{C} 30 \mathrm{sec}, 35$ cycles; GAPDH, $94^{\circ} \mathrm{C} 30 \mathrm{sec}, 54^{\circ} \mathrm{C} 30 \mathrm{sec}, 72^{\circ} \mathrm{C} 20 \mathrm{sec}, 25$ cycles. GAPDH was used as an internal control. Product $(5-\mu \mathrm{l})$ was added to the $1.5 \%$ agarose gel electrophoresis and images were taken. The RT-PCR sequences of primers and the size of the sequences are shown in Table I.

Analysis of P-gp function in SW1990/Gem by Rhodamine123 (Rh123) efflux experiment (flow cytometric analysis). After SW1990/Gem cells were incubated with emodin and gemcitabine alone or combination for $48 \mathrm{~h}$, they were resuspended in medium $\left(1 \times 10^{6} / \mathrm{ml}\right)$, then Rhodamine 123 staining solution $10 \mu \mathrm{g} / \mathrm{ml}$ was added and cultured in an incubator with $37^{\circ} \mathrm{C} 5 \% \mathrm{CO}_{2}$ for $30 \mathrm{~min}$, centrifuged and washed with medium twice, resuspended in medium and incubated in the incubator for $120 \mathrm{~min}$, centrifuged again and washed with PBS twice, measured by flow cytometry at $488 / 530 \mathrm{~nm}$. This experiment was repeated three times.

Statistical analysis. Data were expressed as the mean \pm SD and evaluated by SPSS16.0. The differences were considered to be statistically significant at $\mathrm{P}<0.05$.

\section{Results}

Biological properties of the gemcitabine-resistant cell line SW1990/Gem and sensitivity testing. We achieved the stable passage resistance cell line after 10 months via in vitro culture, after incubation without drugs for 2 months, compared with parental cell line SW1990, the SW1990/ Gem changed significant in morphology. Under light
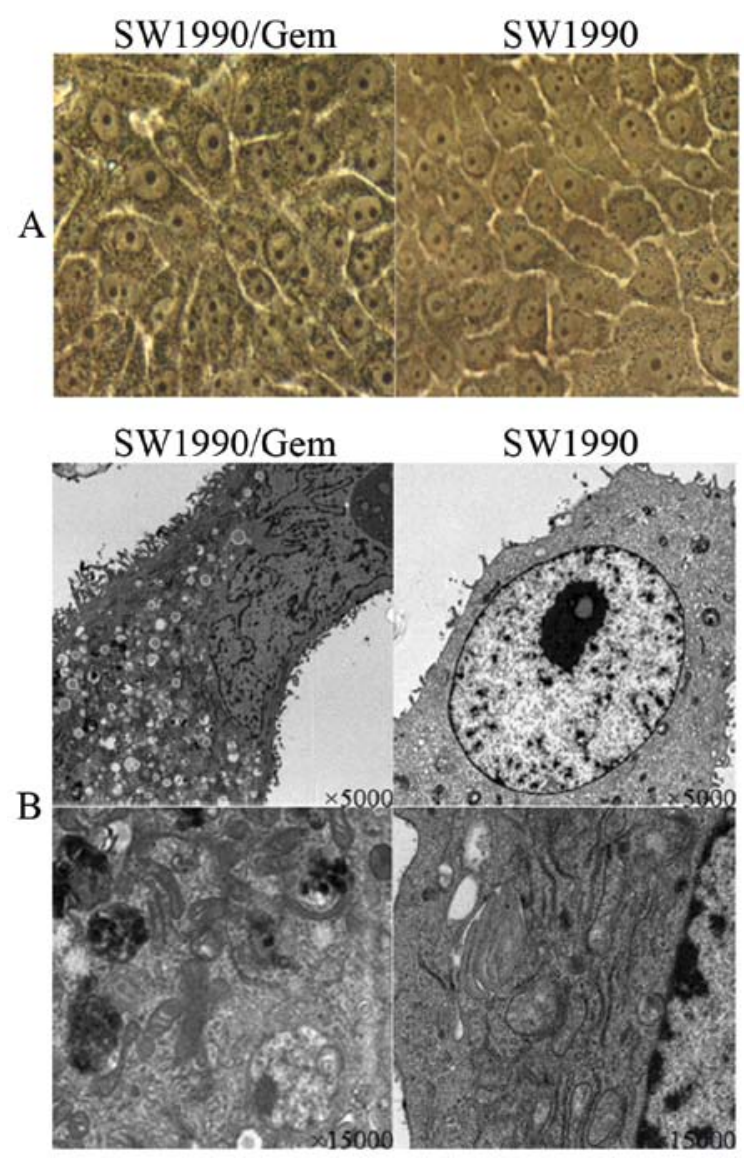

Figure 1. The changes of biological properties. (A) Compared with SW1990, the volume of SW1990/Gem cells increased, SW1990/Gem cell size varied and the granular substances increased, cells with more nucleoli increased. (B) Compared with SW1990, microvilli at the surface of the SW1990/Gem cell membranes increased, the SW1990/Gem cell surface area increased, cell organs in the cytoplasm increased, mitochondria cristaes were disordered, vacuoles were found in the cell matrix, endoplasmic reticulum and the vacuole structures in the cytoplasm were increased.

microscope (x400) (Fig. 1A), the volume of SW1990/Gem cells increased, was different in size and the granular substances increased, SW1990/Gem cells with more nucleoli increased. Under electron microscopy (x5,000 and $\mathrm{x} 15,000$ ) (Fig. 1B), microvilli at the surface of the SW1990/Gem cell membranes increased, the SW1990/ Gem cell surface area increased, cell organelles in the 


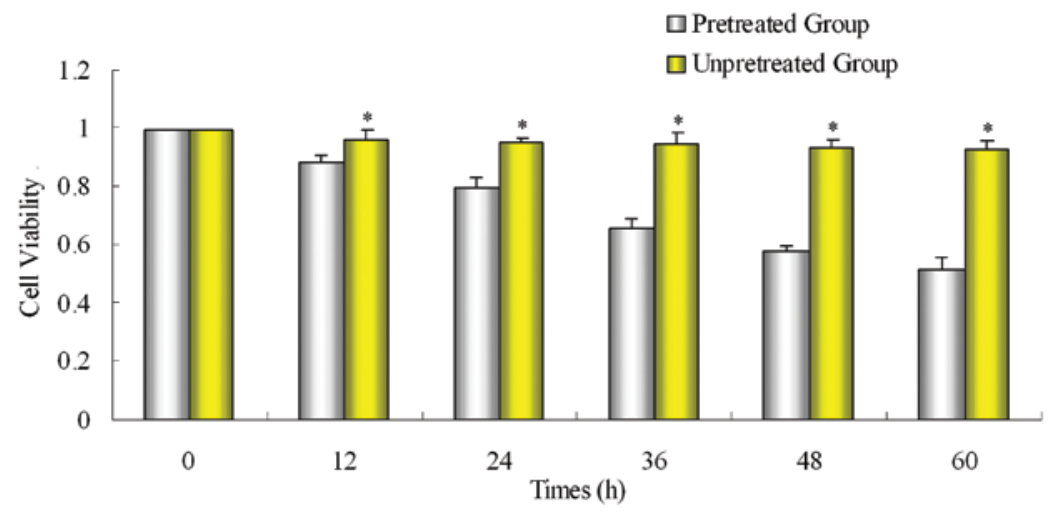

Figure 2. SW1990/Gem cells pretreated with emodin at $10 \mu \mathrm{M}$ for different periods $(12,24,36,48$ and $60 \mathrm{~h})$, and then treated with gemcitabine for $48 \mathrm{~h}(20 \mu \mathrm{M})$, cell proliferation was analyzed by MTT, the group pretreated with emodin decreased the cell viability of SW1990/Gem in a time-dependent manner, compared with unpretreated group, ${ }^{*} \mathrm{P}<0.05$.
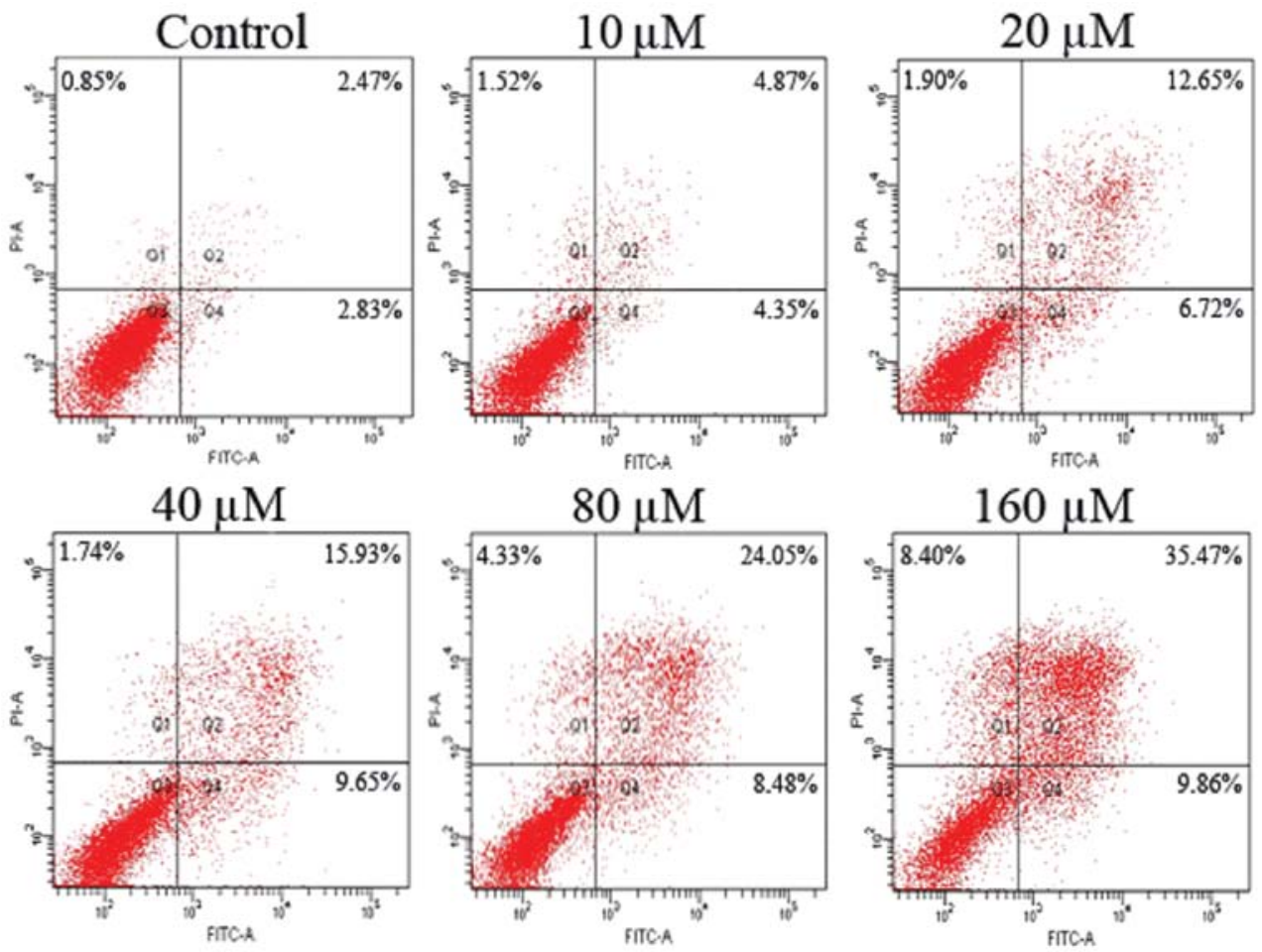

Figure 3. SW1990/Gem cells were treated with different concentrations of emodin (10, 20, 40, 80 and $160 \mu \mathrm{M})$ for $48 \mathrm{~h}$, cell apoptosis was analyzed by FCM. Emodin promoted SW1990/Gem cells apopotosis in a dose-dependent manner.

cytoplasm increased, mitochondria cristaes were disordered, vacuoles were also found in the SW1990/Gem cell matrix, endoplasmic reticulum and the vacuole structures in cytoplasm were increased. The gemcitabine-resistant cell line SW1990/Gem 50\% inhibitory concentration $\left(\mathrm{IC}_{50}\right)$ was $1267.53 \pm 26.78 \mu \mathrm{M}$, the resistance index was 48.63 . The resistant cell line SW1990/Gem showed significant resistance to gemcitabine.

After SW1990/Gem cells were pretreated with emodin, the sensitivity to gemcitabine was significantly enhanced. Pretreated group was pretreated with emodin and then treated with gemcitabine for $48 \mathrm{~h}$, unpretreated group was treated with only gemcitabine for $48 \mathrm{~h}$. Compared with the unpretreated group, the inhibiting effect of gemcitabine on proliferation of gemcitabine-resistant cell line SW1990/Gem was significantly enhanced in pretreated group (Fig. 2).

Promoting effect of emodin on SW1990/Gem cell apoptosis. SW1990/Gem cells were treated with different concentrations of emodin $(10,20,40,80$ and $160 \mu \mathrm{M})$ for $48 \mathrm{~h}, \mathrm{FCM}$ was applied to analyze cell apoptosis. As Fig. 3 showed that emodin promoted cell apoptosis of gemcitabine-resistant cell line SW1990/Gem in a dose-dependent manner.

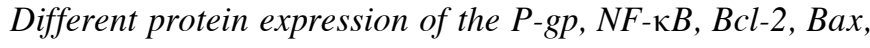
cytochrome-C (cytosol), caspase-9 and -3 in SW1990/Gem and SW1990 cells. Determined the basal expression of protein P-gp, NF- $\mathrm{KB}, \mathrm{Bcl}-2$, Bax, cytochrome-C (cytosol), caspase-9 and-3 in SW1990/Gem cells and SW1990 cells by Western blotting. 

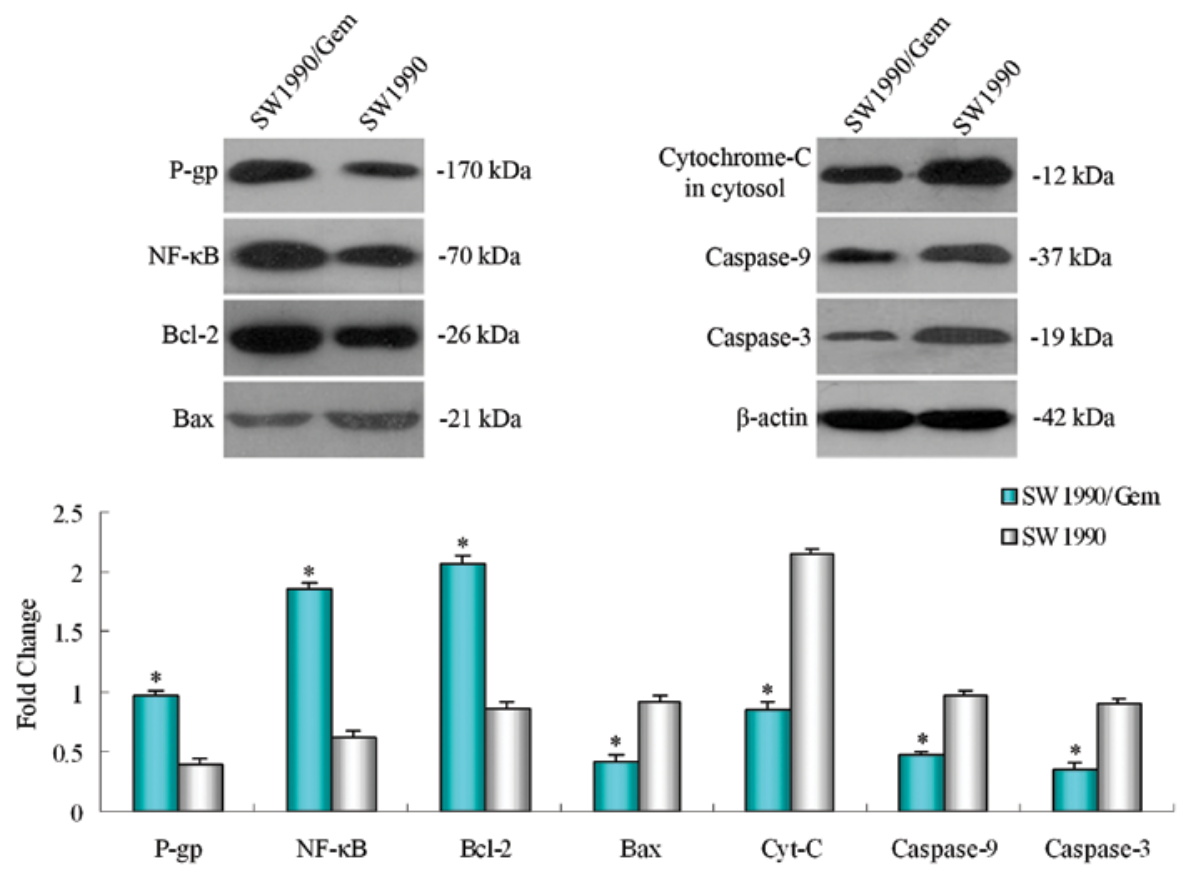

Figure 4. The protein expression was detected by Western blotting. Increased expression was seen of P-gp, NF- $\mathrm{kB}$ and Bcl-2 in SW1990/Gem, decreased expression of Bax, cytochrome-C (cytosol), caspase-9 and -3 in SW1990/Gem. Compared with SW1990, ${ }^{*} \mathrm{P}<0.05$.
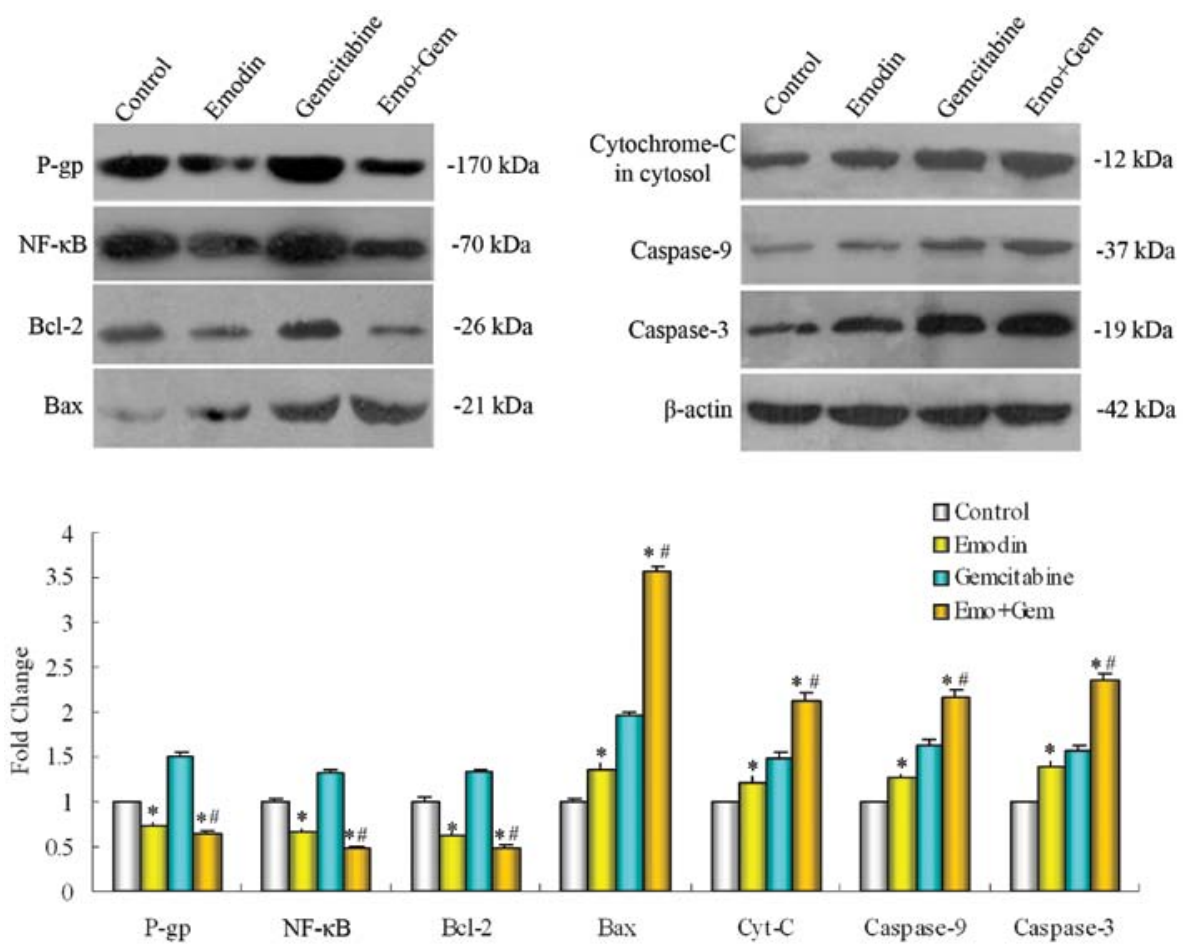

Figure 5. The protein expression was detected by Western blotting. Emodin alone and combined with gemcitabine down-regulated the protein expression of P-pg, $\mathrm{NF}-\mathrm{kB}$ and Bcl-2, and up-regualted the expression of cytochrome-C (cytosol), caspase-9 and -3. Compared with control group, "P<0.05; compared with gemcitabine group, ${ }^{\#} \mathrm{P}<0.05$.

Compared with parental cell line SW1990, the expression of multidrug-resistance gene encoding protein $\mathrm{P}$-gp, apoptosis regulatory protein in mitochondrial pathway Bcl-2 and the NF- $\mathrm{KB}$ increased in the SW1990/Gem cells, while the expression of Bax regulated by $\mathrm{Bcl}-2$ in mitochondrial pathway, cytochrome-C (cytosol), the caspase- 9 and -3 of caspase family decreased obviously (Fig. 4).
Effect of emodin on NF- $\mathrm{KB}$ and its related proteins in SW1990/ Gem cells. SW1990/Gem cells were treated with emodin $(10 \mu \mathrm{M})$ alone or combined with gemcitabine $(20 \mu \mathrm{M})$ for $48 \mathrm{~h}$. The expression of protein was measured by Western blotting. As shown in Fig. 5, emodin alone or combined with gemcitabine down-reguglated the expression of NF- $\mathrm{kB}$ in SW1990/Gem cells, and then decreased the NF- $\mathrm{KB}$ regulated multidrug resis- 

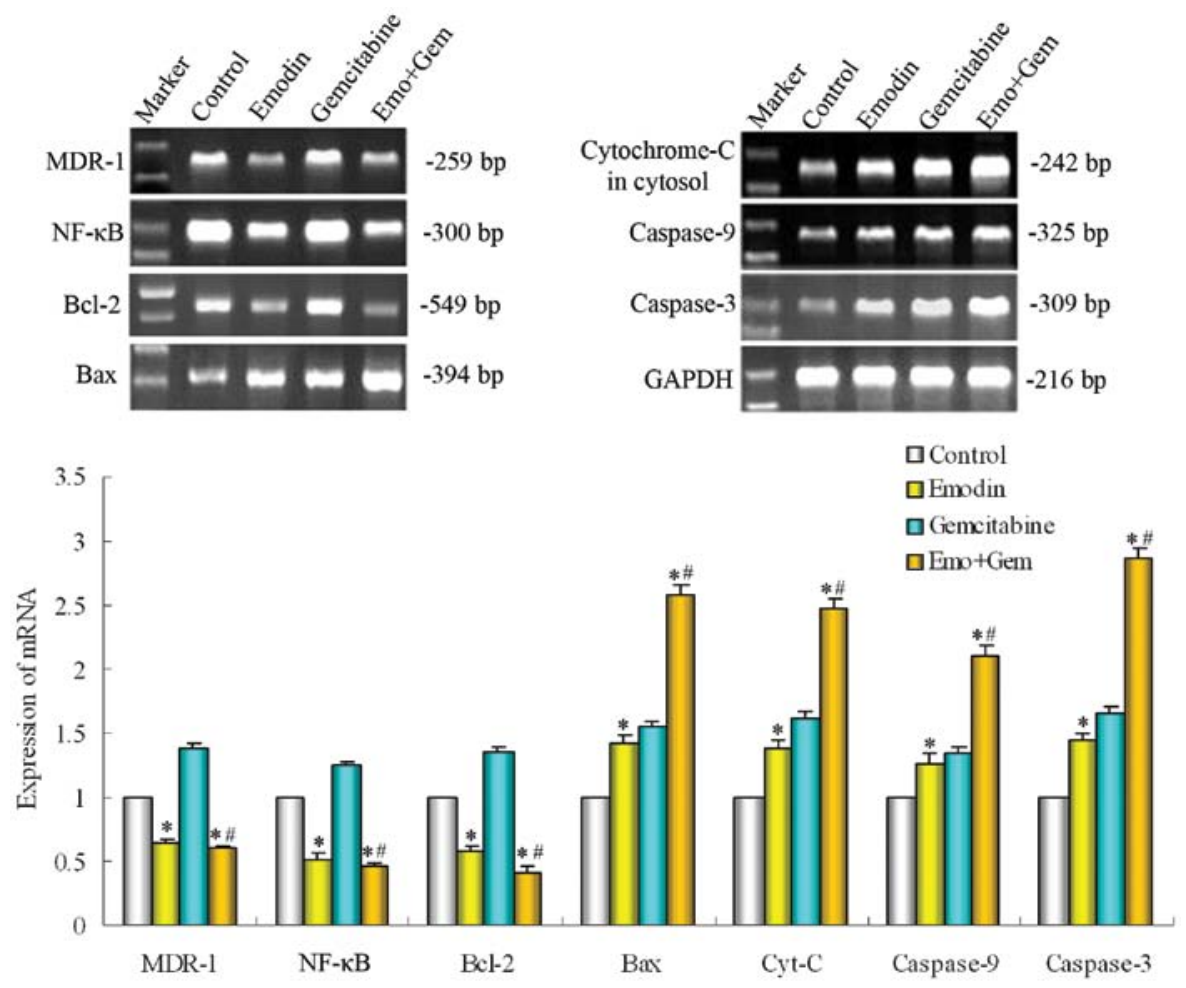

Figure 6. The mRNA expression was detected by RT-PCR, emodin alone and combined with gemcitabine could down-regulate the expression of MDR-1, NF- $\mathrm{kB}$ and Bcl-2, up-regulate the expression of Bax, cytochrome-C (cytosol), caspase-9 and -3. Compared with control group, " $\mathrm{P}<0.05$; compared with gemcitabine group, ${ }^{\#} \mathrm{P}<0.05$.
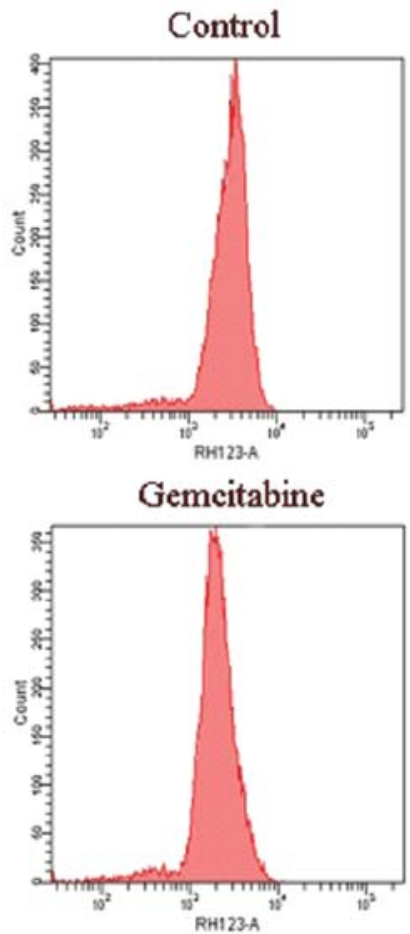
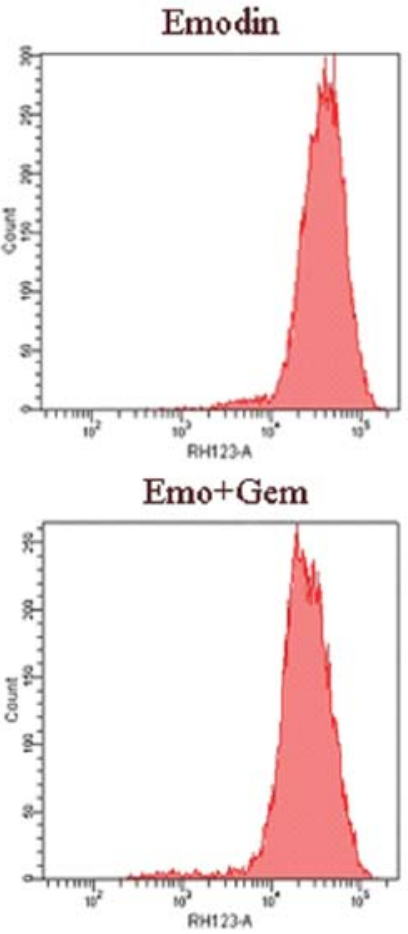

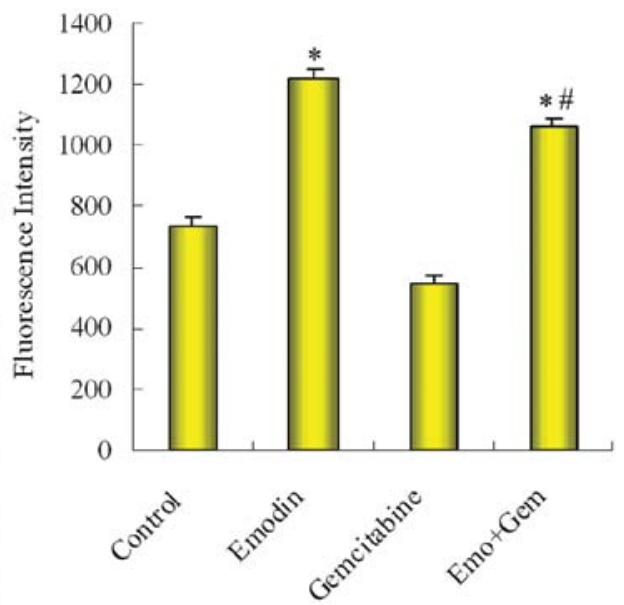

Figure 7. The P-gp function in SW1990/Gem was observed by Rhodamine123 (Rh123) efflux experiment (flow cytometric analysis). Emodin combined with gemcitabine up-regulated the fluorescence intensity. Compared with the control group, ${ }^{*} \mathrm{P}<0.05$; compared with gemcitabine group, ${ }^{\text {"P }}<0.05$.

tance protein P-gp and the Bcl-2 in mitochondrial pathway, then increased the expression of Bax and cytochrome-C (cytosol) regulated by $\mathrm{Bcl}-2$ in mitochondrial pathway. Caspase cascade was triggered followed by the apoptosis of pancreatic cancer cells, thus, inhibition of pancreatic cancer growth and promotion of apoptosis occurred. 
Effect of emodin on the $m R N A$ of $N F-\kappa B$ and its regulated genes in SW1990/Gem cells. The SW1990/Gem cells were treated with emodin $(10 \mu \mathrm{M})$ alone or combined with gemcitabine $(20 \mu \mathrm{M})$ for $48 \mathrm{~h}$. The expression of gene was measured by PT-PCR. As shown in Fig. 6, emodin alone or combined with gemcitabine both down-regulated the expression of NF- $\mathrm{kB}$, then down-regulated the gene expression of MDR-1 and Bcl-2, but up-regulated the expression of Bax, cytochrome-C, caspase- 9 and -3 , these were in line with the proteins change and validated the effect of emodin further.

Effect of emodin on the the function of P-gp in SW1990/Gem cells. The level of rhodamine efflux function was determined by FCM after SW1990/Gem cells were treated with emodin alone and then combined with gemcitabine. As shown in Fig. 7 , the fluorescence intensity was $734.62 \pm 25.74$ in control group cells, $1225.28 \pm 28.55$ in emodin-treated group, $545.23 \pm 28.27$ in gemcitabine-treated group cells and $1068.44 \pm 22.85$ in the combined group. Compared with control group, emodin decreased the function of P-gp; compared with gemcitabinetreated group, the combined group also decreased function of P-gp.

\section{Discussion}

Pancreatic cancer is a common gastrointestinal tumor, because most patients are diagnosed at advanced stage, the surgical resection rate is low and chemo-therapy is the most critical treatment. Gemcitabine is the standard chemotherapeutic agent for advanced pancreatic cancer, but in clinical work the treatment effect is not ideal due to the increase of gemcitabine-induced drug resistance. The rate of 5-year overall survival is less than $5 \%$ and drug resistance is the main reason for the failure of the chemo-treatment in pancreatic cancer (6). According to reports, the mechanism of resistance to chemotherapy may be associated with increased drug cellular efflux by overexpressed P-gp encoded by multidrug resistance gene (MDR-1) and deregulated expression of anti-apoptotic or pro-apoptotic molecules $(20,21)$, may also be associated with multidrug resistance-associated protein (MRP) (22).

As a traditional Chinese medicine, emodin not only has anti-tumor effect (15), but also can enhance the anti-tumor effect of the chemo-therapy drugs $(16,23,24)$. It has been reported that emodin sensitizes the ovarian cancer cells and the gallbladder cancer cells to chemotherapeutic agents $(25,26)$. However, reports on whether emodin can reverse the chemotherapeutic drug resistance in pancreatic cancer are rare. Our group first reported that emodin sensitized resistant cell to gemcitabine through inhibiting the expression of NF-KB in SW1990/Gem cells (18). In this study, we established the gemcitabine-resistant cell line SW1990/Gem with intermittently increasing the concentration of gemcitabine in the culture medium for 10 months, then calculated the resistance index and observed cell morphology. In the follow-up, SW1990/Gem cells were pretreated with emodin $(10 \mu \mathrm{M})$ for different periods and then treated with gemcitabine (20 $\mu \mathrm{M})$ for $48 \mathrm{~h}$, cell viability was detected by MTT. The results showed that inhibition effect of gemcitabine on proliferation of drug-resistant cell line SW1990/Gem was significantly enhanced after cells were pretreated with emodin. FCM results showed that emodin could promote cell apoptosis in drug-resistant cell line SW1990/Gem. Western blotting detected the basal expression of P-gp, NF- $\kappa \mathrm{B}, \mathrm{Bcl}-2$, Bax, cytochrome-C (cytosol), caspase-9 and -3 in SW1990/Gem cells and SW1990 cells, it was found that compared with parental cell line SW1990, the expression of P-gp, NF- $\mathrm{kB}$ and Bcl-2 was increased in the SW1990/Gem cells, while the expression of Bax, cytochrome-C, caspase- 9 and -3 was decreased. Based on this, we furher investigated the potential molecule mechanism of reversing the resistance effect of gemcitabine-resistant pancreantic cancer cell line SW1990/Gem by emodin, possibly it is via decreasing the function of P-gp and the mitochondrial apoptosis pathway.

P-gp encoded by multidrug resistance gene-1 (MDR-1) is a kind of transmembrane glycoprotein, belongs to transporter protein superfamily ABC and has the ATP-dependent drug efflux function (22). P-gp can induce drug resistance due to decrease in the cellular chemotherapeutic drug under effective concentration through pumping the chemotherapeutic agents out of the cells against the concentration (27). Therefore, MDR-1/P-pg plays an important role in tumor chemotherapeutic resistance $(28,29)$. According to reports, nuclear transcription factor NF- $\mathrm{KB}$ induces resistance of tumor cells through down-regulating the expression of MDR-1 mRNA (30). Other reports stated that the decrease of P-gp in expression and function reversed the chemotherapeutic resistance in breast cell line MCF-7, through the inhibition of MDR-1 expression induced by the decrease of expression and activity of NF- $\mathrm{KB}$ (31). In this study, the levels of gene and protein of the NF- $\kappa B$ and MDR-1 (P-gp) were decreased both in emodin group and in gemcitabine group. Rhodamine efflux experiments indicated that the function of P-gp was decreased both in emodin group and combination group. The decrease of expression and function of P-gp directly increased the intracellular drug concentration, and this may be partly the response to the reversion of the gemcitabine-resistance in pancreatic cancer.

Apoptosis defection is another important reason for drug resistance. Chemotherapeutic agents, as one of the major treatments of cancer, kill tumor cells mainly through inducing apoptosis, and the defection of apoptosis is one of the important reasons for drug-resistance due to insensitive of the tumor to chemotherapy (32).

Bcl-2 protein family is very important in apoptosis, the anti-apoptotic protein $\mathrm{Bcl}-2$ and pro-apoptotic protein Bax are the major members in this family. Bcl-2 and Bax also play very important roles in mitochondrial pathway (33), the downregulation of Bcl-2 and the up-regulation of Bax can induce the release of cytochrome-C (cytosol) from mitochondria, trigger the activity of caspase- 3 and -9 and finally cause cell apoptosis (34). This study verified that the expression of Bcl-2 in SW1990/ Gem was significantly higher than SW1990, but the expression of Bax and cytochrome-C were significantly lower suggesting that the mitochondrial receptor pathway may be involved in the formation of gemcitabine-resistance. From the level of gene and protein expression, we further found that emodin decreased the expression of Bcl-2, increased the expression of Bax and cytochrome-C, this was most obvious in combination group suggesting that low concentration of emodin could reverse the 
increase of Bcl-2 and the decrease of Bax induced by resistance, but had no significant pro-apoptotic effect, and therefore enhanced the sensitivity of gemcitabine-resistant pancreatic cells to gemcitabine.

$\mathrm{NF}-\mathrm{kB}$ is a family of ubiquitous transcription factors involving immunity, inflammation, regulation of cell growth, differentiation, apoptosis, and tumor metastasis. In recent reports, NF- $\mathrm{\kappa B}$ is shown closely related to tumor resistance to chemotherapy. As previous studies show, down-regulation of anti-apoptotic protein is one of the mechanisms that NF- $\mathrm{kB}$ takes part in apoptosis and induces apoptosis (35). Banerjee et al have reported that NF- $\mathrm{kB}$ caused the resistance of pancreatic cancer through up-regulating the expression of anti-apoptotic proteins (XIAP, Bcl-xL, Survivin) (21). Another report shows that NF- $\mathrm{kB}$ induced the resistance of breast cancer by increasing the expression of anti-apoptotic protein $\mathrm{Bcl}-2$ and decreasing the expression of pro-apoptotic protein Bax (36). Also, there are reports that NF- $\mathrm{kB}$ can overcome the chemotherapeutic resistance through down-regulating of expression of anti-apoptotic protein $\mathrm{Bcl}-2$ family (37). Our study suggested that NF-кB participated in the formation of tumor resistance via multidrug resistance encoding protein P-gp and Bcl-2, with Bax that existed in mitochondrial apoptosis pathway. In this study we found that emodin reversed the gemcitabine resistance effect in pancreatic cancer, the action might be associating with down-regulation of NF- $\mathrm{kB}$ expression, and lowering the expression of P-gp and Bcl-2, increasing Bax expression.

In conclusion, emodin can effectively reverse the resistance effect of pancreatic cancer to gemcitabine. The potential mechanisms are 1) the decrease in the expression and function of P-gp, thus causing decrease of the efflux of drug and then increasing the intracellular drug concentration, thus the treatment effect was enhanced, 2) the down-regulation of Bcl-2 expression in mitochondrial apoptosis pathway and the up-regulation of Bax in mitochondrial pathway, followed by the occurrence of apoptosis.

\section{Acknowledgements}

We are grateful for funding support from the Administration of Traditional Chinese Medicine of Zhengjing Province, China (Grant No. 2011ZZ010) and The National Natural Science Foundation of China (Grant No. 81173606). We thank the entire staff of the Animal Experimental Center in Wenzhou Medical College and of Scientific Research platform of the Second Affiliated Hospital of Wenzhou Medical College for helpful assistance.

\section{References}

1. Rivera F, Lopez-Tarruella S, Vega-Villegas MA and Salcedo M: Treatment of advanced pancreatic cancer: from gemcitabine single agent to combinations and targeted therapy. Cancer Treat Rev 35: 335-339, 2009.

2. Jemal A, Siegel R, Ward E, Murray T, Xu J and Thun MJ: Cancer statistics, 2007. CA Cancer J Clin 57: 43-66, 2007.

3. Jemal A, Siegel R, Xu J and Ward E: Cancer statistics, 2010. CA Cancer J Clin 60: 277-300, 2010.

4. Burris HA, Moore MJ, Andersen J, Green MR, et al: Improvements in survival and clinical benefit with gemcitabine as first-line therapy for patients with advanced pancreas cancer: a randomized trial. J Clin Oncol 15: 2403-2413, 1997.
5. Yu C, Zhang X, Sun G, Guo X, et al: RNA interference-mediated silencing of the polo-like kinase 1 gene enhances chemosensitivity to gemcitabine in pancreatic adenocarcinoma cells. J Cell Mol Med 12: 2234-2249, 2008.

6. El Maalouf G, Le Tourneau C, Batty GN, Faivre S and Raymond E: Markers involved in resistance to cytotoxics and targeted therapeutics in pancreatic cancer. Cancer Treat Rev 35: 167-174, 2009.

7. Tada M, Arizumi M, Nakai Y, Sasaki T, et al: Efficacy of gemcitabine for locally advanced pancreatic cancer: comparsion with 5-fuorouracil-based chemoradiotherapy. Chemotherapy 54: 302-308, 2008.

8. Basu S, Ghosh A and Hazra B: Evaluation of the antibacterial activity of Ventilago madraspatana Gaertn., Rubia cordifolia Linn. and Lantana camara Linn.: isolation of emodin and physcion as active antibacterial agents. Phytother Res 19: 888-894, 2005.

9. Manojlovic NT, Solujic S, Sukdolak S, et al: Antifungal activity of Rubia tinctorum, Rhamnus frangula and Caloplaca cerina. Fitoterapia 76: 244-246, 2005.

10. Alves DS, Perez-Fons L, Estepa A, et al: Membrane-related effects underlying the biological activity of the anthraquinones emodin and barbaloin. Biochem Pharmacol 68: 549-561, 2004.

11. Mbwambo ZH, Apers S, Moshi MJ, et al: Anthranoid compounds with antiprotozoal activity from Vismia orientalis. Planta Med 70: 706-710, 2004.

12. Li HL, Chen HL, Li H, et al: Regulatory effects of emodin on NF-kappaB activation and inflammatory cytokine expression in RAW 264.7 macrophages. Int J Mol Med 16: 41-47, 2005.

13. Kitano A, Saika S, Yamanaka O, Ikeda K, Okada Y, et al: Emodin suppression of ocular surface inflammatory reaction. Invest Ophthalmol Vis Sci 48: 5013-5022, 2007.

14. Kuo YC, Tsai WJ, Meng HC, Chen WP, et al: Immune reponses in human mesangial cells regulated by emodin from Polygonum hypoleucum Ohwi. Life Sci 68: 1271-1286, 2001.

15. Cai J, RazzakA, Hering J, Saed A, et al: Feasibility evaluation of emodin (rhubarb extract) as an inhibitor of pancreatic cancer cell proliferation in vitro. J Parenter Enteral Nutr 32: 190-196, 2008.

16. Chen H, Wei WT, Guo YF, Liu A, et al: Enhanced effect of gemcitabine by emodin against pancreatic cancer in vivo via cytochrome C-regulated apoptosis. Oncol Rep 25: 1253-1261, 2011.

17. Jung HA, Chung HY, Yokozawa T, et al: Alaternin and emodin with hydroxyl radical inhibitory and/or scavenging activities and hepatoprotective activity on tacrine-induced cytotoxicity in HepG2 cells. Arch Pharm Res 27: 947-953, 2004.

18. Liu A, Chen H, Tong H, et al: Emodin potentiates the antitumor effects of gemcitabine in pancreatic cancer cells via inhibition of nuclear factor-kappaB. Mol Med Rep 4: 221-227, 2011.

19. Hansen MB, Nielsen SE and Berg K: Re-examination and further development of a precise and rapid dye method for measuring cell growth/cell kill. J Immunol Methods 119: 203-210, 1989.

20. Hao ZM, Li XH, Qiao TD, Du R, Hong L and Fan DM: CIAPIN1 confers multidrug resistance by upregulating the expression of MDR-1 and MRP-1 in gastric cancer cells. Cancer Biol Ther 5: 261-266, 2006.

21. Banerjee S, Wang Z, Kong D and Sarkar FH: 3,3'-Diindolylmethane enhances chemosensitivity of multiple chemotherapeutic agents in pancreatic cancer. Cancer Res 69: 5592-5600, 2009.

22. Gao S, Liu Q, Wang X, Lin B and Zhang S: Effects of Lewis $Y$ antigen on the gene expression of multiple drug resistance-associated proteins in human ovarian cancer RMG-I-H cells. Med Oncol 27: 960-967, 2010.

23. Wang ZH, Chen H, Guo HC, Tong HF, et al: Emodin antitumor efficacy by the combination of emodin and gencitabine against human pancreatic cancer cells via downregulation of the expression of XIAP in vitro and in vivo. Int J Oncol 39: 1123-1131, 2011.

24. Wei WT, Chen H, Ni ZL, Liu HB, et al: Antitumor and apoptosispromoting properties of emodin, an anthraquinone derivative from Rheum officinale Baill, against pancreatic cancer in mice via inhibition of Akt activation. Int J Oncol 39: 1381-1390, 2011.

25. Wang W, Sun YP, Huang XZ, He M, Chen YY, et al: Emodin enhances sensitivity of gallbladder cancer cells to platinum drugs via glutathion depletion and MRP1 downregulation. Biochem Pharmacol 79: 1134-1140, 2010.

26. Li J, Liu PS, Mao HL, et al: Emodin sensitizes paclitaxel-resistant human ovarian cancer cells to paclitaxel-induced apoptosis in vitro. Oncol Rep 21: 1605-1610, 2009.

27. Leonessa F and Clarke R: ATP binding cassette transporters and drug resistance in breast cancer. Endocr Relat Cancer 10: 43-73, 2003. 
28. Takakuwa O, Oguri T, Ozasa H, Uemura T, Kasai D, et al: Overexpression of MDR1 in amrubicinol-resistant lung cancer cells. Cancer Chemother Pharmacol 68: 669-676, 2010.

29. Dong Y, Shao S, Hu J and Yang P: Reversal effect of Raf-1/Mdr-1 siRNAs co-transfection on multidrug resistance in KBv200 cell line. Oral Oncol 45: 991-997, 2009.

30. Bentires Alj M, Barbu V, Fillet M, et al: NF-kappaB transcription factor induces drug resistance through MDR1 expression in cancer cells. Oncogene 22: 90-97, 2003.

31. Chen C, Shen HL, Yang J, Chen QY and Xu WL: Preventing chemoresistance of human breast cancer cell line, MCF-7 with celecoxib. J Cancer Res Clin Oncol 137: 9-17, 2011.

32. Hannun YA: Apoptosis and the dilemma of cancer chemotherapy. Blood 89: 1845-1853, 1997.

33. Gross A, McDonnell JM and Korsmeyer SJ: BCL-2 family members and the mitochondria in apoptosis. Genes Dev 13: 1899-1911, 1999.
34. Qi FH, Inagaki Y, Gao B, Cui X and Xu HL: Bufalin and cinobufagin induce apoptosis of human hepatocellular carcinoma cells via Fas- and mitochondria-mediated pathways. Cancer Sci 102: 951-958, 2011.

35. Leger DY, Liagre B and Beneytout JL: Role of MAPKs and NF-kappaB in diosgenin-induced megakaryocytic differentiation and subsequent apoptosis in HEL cells. Int J Oncol 28: 201-207, 2006.

36. Bachmeier B, Fichtner I,Killian PH,Kronski E, et al: Development of resistance towards artesunate in MDA-MB-231 human breast cancer cells. PLoS One 6: e20550, 2011.

37. Kumar MV, Shirley R, Ma Y and Lewis RW: Role of genomicsbased strategies in overcoming chemotherapeutic resistance. Curr Pharm Biotechnol 5: 471-480, 2004. 